\title{
A CONSTRUÇÃO DA CIDADANIA A PARTIR DO RECONHECIMENTO DOS DIREITOS DOS TRABALHADORES: UMA ANÁLISE DO TRABALHO NA MINERAÇÃO NO BRASIL
}

\author{
Rafael da Silva Almeida* \\ Suzy Elizabeth Cavalcante Koury ${ }^{* *}$
}

\section{RESUMO:}

Busca-se analisar se as condições de trabalho na atividade de mineração atendem o ideal de cidadania proclamado pela $\mathrm{CF} / 88$. Parte da evolução histórica da construção da cidadania no Brasil e enfoca as lutas de classe e sua importância para o reconhecimento da igualdade substancial. Procede-se à comparação das condições impostas aos trabalhadores da mineração no século XIX, a partir da obra "Germinal", de Zola, e, após, perquire-se se é possível afirmar que há, atualmente, plena afirmação da cidadania dos trabalhadores na mineração no Brasil. Utiliza-se do método dedutivo de pesquisa efetuada pela revisão bibliográfica de doutrinas pertinentes ao tema.

Palavras-chave: Trabalhador; Mineração; Lutas de classe; Cidadania; Direito.

\section{CONSTRUCTION OF CITIZENSHIP ON THE RECOGNITION OF LABOR RIGHTS: AN ANALYSIS OF MINING WORK IN BRAZIL}

\begin{abstract}
:
It seeks to analyze if the working conditions in the mining activity meet the ideal of citizenship proclaimed by the CF /88. Part the historical evolution of the construction citizenship Brazil and focuses on class struggles and their importance for the recognition of substantial equality. The comparison of conditions imposed on mining workers the nineteenth century, based on Zola's "Germinal", and afterwards, it's possible to affirm that there is now full affirmation of the citizenship of workers in the mining in Brazil. We use the deductive method research carried out by the bibliographic review doctrines pertinent to the theme.
\end{abstract}

Keywords: Worker; Mining; Class fights; Citizenship; Right.

\section{INTRODUÇÃO.}

A cidadania, concebida como um direito que engloba a ampla liberdade, a emancipação política real e a dignidade de existência plena, nem sempre é assegurada de fato.

\footnotetext{
Especialização em Direito do Trabalho e Processo do Trabalho pela Faculdade Rolim de Moura- FAROL. Mestrando em Direito, Políticas Públicas e Desenvolvimento Regional pelo Centro Universitário do Pará CESUPA. E-mail: rafinha_allmeida@ @otmail.com. O presente trabalho foi realizado com apoio da Coordenação de Aperfeiçoamento de Pessoal de Nível Superior - Brasil (CAPES) - Código de Financiamento 001.

** Doutora em Direito pela Faculdade de Direito da UFMG. Desembargadora Presidente do TRT da $8^{\text {a }}$ Região. Professora dos Cursos de Graduação e de Mestrado do Centro Universitário do Pará - CESUPA. E-mail: suzykoury@gmail.com.
} 
Marshall (1967), ao referir-se a efetividade dos direitos civis, entendidos como liberdades reconhecidas constitucionalmente como direitos fundamentais do homem, já no século XVIII apontava para o esvaziamento do conteúdo da liberdade, quando não atrelada a uma igualdade substancial, pois dizer ao miserável que ele possui o mesmo direito de propriedade que o rico, certamente, àquele, pareceria um impropério.

É a partir dessa constatação que parte o presente estudo, que pretende ressaltar a importância da cidadania para o desenvolvimento de uma ordem legal efetivamente democrática em dada sociedade, com enfoque nos trabalhadores da mineração.

Para tanto, busca-se averiguar a evolução histórica da construção da cidadania no Brasil, com base nos estudos desenvolvidos por T. H. Marshall (1967) e sua divisão lógica e cronológica dos elementos civil, político e social, construída a partir da realidade europeia.

A pergunta que se pretende responder é: a cidadania garantida pela Constituição Federal de 1988 é assegurada no contexto real do embate entre o capital e a força de trabalho, na atividade de mineração?

Optou-se por utilizar o método dedutivo de pesquisa efetuada pela revisão bibliográfica de doutrinas pertinentes ao tema, tanto nacionais quanto estrangeiras. $\mathrm{O}$ artigo foi dividido em três partes para melhor distribuição de seu conteúdo.

Na primeira parte, tendo por base os estudos do sociólogo T. H. Marshall (1967), o trabalho aborda a construção da cidadania a partir dos três elementos por eles propostos, a saber: o civil, o político e o social, que teriam correspondência cronológica, respectivamente, com os séculos XVIII, XIX e XX, explicando como se deu o reconhecimento de cada um deles no desenvolvimento da sociedade européia moderna.

Ainda nesse primeiro momento, será abordado o problema decorrente das desigualdades sociais enfrentadas pela classe operária na Europa dos fins do século XIX, utilizando-se, para tanto, a obra literária francesa "Germinal”, de Ėmile Zola na qual descreve com cruel lealdade a dura realidade do trabalho em uma mina de carvão no norte da França, em que um trabalhador chamado Étienne se vê na contingência de escolher entre o mísero salário e a própria sobrevivência. Esta realidade resultou em violentos conflitos com a classe proprietária, que serviram à germinação dos direitos sociais.

$\mathrm{Na}$ segunda parte, revela-se a história da construção da cidadania brasileira pela visão de José Murilo de Carvalho (2012), destacando-se algumas conquistas quanto aos direitos civis, políticos e sociais, que são elementos componentes da cidadania, com destaque 
ao social e ao fato de que, no Brasil, os direitos de cidadania somente foram pleiteados com vigor e reconhecidos a partir do século $\mathrm{XX}$, pelo restabelecimento da democracia que se deu por meio das lutas sociais classistas que se intensificaram na década de 1970, culminando com o advento de uma nova ordem constitucional em 1988.

A última parte trata da consolidação dos direitos fundamentais civis, políticos e sociais os quais foram definitivamente reconhecidos pela ordem constitucional vigente inaugurada em 1988, que, em termos teóricos, aproxima-se do conceito ideal de Marshall (1967).

Por este viés, o estudo prossegue na análise da importância do reconhecimento normativo-constitucional dos direitos sociais - primeiro elemento da cidadania brasileira segundo Carvalho (2012) - especialmente os trabalhistas, tendo-se focado a análise no setor da mineração no Brasil, o mesmo descrito por Zola em Germinal, buscando responder se, hoje, há a garantia a esses trabalhadores do efetivo exercício da cidadania.

\section{A CONSTRUÇÃO DA CIDADANIA ENQUANTO DIREITO FUNDAMENTAL.}

\subsection{A EVOLUÇÃO HISTÓRICA DO DIREITO À CIDADANIA.}

Conforme Marshall (1967), a cidadania compõe-se dos três elementos já mencionados - civil, político e social -, cuja construção, por tratar-se de um fenômeno histórico, pode ser dividida em três momentos distintos. O primeiro corresponde ao reconhecimento dos direitos civis, no século XVIII, especialmente o direito de liberdade (liberdade de ir e vir, de pensamento, de fé, de posse, de contratar) e, ainda, o direito à justiça.

O elemento político caracteriza-se pelo direito de participar do exercício do poder político do Estado, estando apto a votar e a ser votado, que se consolidou no século XIX, com o reconhecimento do sufrágio universal.

O terceiro elemento, qual seja, o social, segundo Marshall (1967), abrange desde o direito a um mínimo de bem-estar econômico e segurança, até o de "participar por completo da herança social e levar uma vida de um ser civilizado de acordo com os padrões que prevalecem na sociedade", reconhecido no século XX.

Marshall (1967) não omite que a questão dos direitos políticos, além de estar atrelada ao status econômico, também sofreu limitações impostas pelos interesses que predominavam 
à época, já que não interessava à classe burguesa que o trabalhador se visse politicamente representado no parlamento inglês, razão pela qual somente se tornaram relevantes na construção da cidadania plena em fins do século XIX quando a classe operária já experimentava certa consciência de sua representatividade.

Como exposto, o primeiro elemento da cidadania diz respeito ao reconhecimento dos direitos civis, que nasceram no século XVIII e já se encontravam consolidados no final do século seguinte, a ponto de Marshall (1967) afirmar que já apresentavam, em seus aspectos essenciais, a aparência atual.

Os direitos civis, essencialmente direitos de liberdade, para Marshall (1967, p. 69) caracterizaram-se em sua formação pela "adição de novos direitos a um status que já existia", pois, na Inglaterra, no século XVII, todos os homens já eram livres, vez que o status servil ligado ao trabalho havia desaparecido e "essa mudança do trabalho servil para o livre, representou um marco fundamental no desenvolvimento tanto da sociedade econômica quanto política".

Historicamente esse momento corresponde à formação do Estado Liberal que fora forjado nas lutas contra o absolutismo e que deu origem à primeira geração de Direitos, Humanos - civis e políticos -, os quais se prestavam, segundo Atria (2005), a proteger o homem contra o "grande Leviatã", o Estado, direitos estes, que foram criados exclusivamente em função da propriedade, como afirma Barreto:

[...] o cerne dos direitos civis e políticos encontrava-se no direito de propriedade, que iria sedimentar, proteger e assegurar o produto do exercício da autonomia, da liberdade e do trabalho humano. Essa a razão pela qual o sistema político e jurídico do Estado liberal organizaram-se em função e para a garantia do exercício das liberdades e das igualdades de uma sociedade de proprietários (BARRETO, 2013, p. 206-207).

O Estado Liberal era fundamentado pelos direitos civis, representando a total liberdade e a igualdade, embora meramente formal, entre os homens, valores que também embasaram o capitalismo de mercado e a formação antagônica e bem definida de duas classes sociais: de um lado, o proletariado, classe trabalhadora assim denominada porque só detinha uma extensa prole e, de outro, a burguesia, detentora do capital, que, por isso, conseguiu a supremacia absoluta sobre aquela. 
As constituições que surgiram nesse período refletiam o ideal do capitalismo, valorizando a liberdade de mercado e a propriedade privada, podendo-se destacar como características marcantes desses séculos (XVIII e XIX):

1) Vivência máxima do capitalismo moderno; 2) valorização sem limites da propriedade privada; 3) da espoliação de uma classe trabalhadora, cuja venda do trabalho era sua única forma de participação no mercado; 4) de lutas sociais sangrentas; 5) subserviência acentuada do Estado à "mão invisível" do mercado; 6) relativa ausência de prestações positivas em favor dos administrados, dentre outros aspectos (BASTOS, 2007,p. 33).

Essa realidade foi retratada no fim do século XIX pela obra literária "Germinal", de Émile Zola (2012), na qual revela o antagonismo entre as classes sociais e a supremacia do capital sobre o trabalho que levou à desumanidade na sua prestação, por meio da descrição das atividades dos trabalhadores na mineração do carvão e as consequentes lutas sociais travadas nesse contexto, as quais tornaram visíveis as mazelas geradas pelo liberalismo econômico implantado desde o início do século anterior, como se verá a seguir.

\subsection{A ATIVIDADE DE MINERAÇÃO NO FINAL DO SÉCULO XIX COMO DESCRITA EM GERMINAL.}

“Olha, não posso queixar-me, os patrões têm sido muito bons, como eles mesmos me disseram" (Zola, 2010, p.404). Esta fala é da matriarca da família Maheu, personagem da obra prima da literatura Francesa "Germinal" de Émile Zola, publicada no ano de 1885, que retrata, com cruel lealdade, condições de trabalho subumanas dos trabalhadores da mineração. Muito além da circunscrita situação da indignidade do trabalho por eles desenvolvido, apresenta a ideia da luta de classes e da germinação dos direitos sociais como precursores da plena cidadania enquanto direito fundamental da pessoa humana.

A citada obra cuida da narrativa de um momento histórico que se passa no final do século XIX, em razão do sistema do laissez faire ${ }^{1}$, que, com os seus ideais de liberdade contratual e igualdade formal entre os homens, permitiu o aviltamento do trabalho humano. Mostra a realidade da família Maheu, a qual forma o núcleo social principal do romance,

\footnotetext{
${ }^{1}$ Laissez-faire é expressão escrita em francês que simboliza o liberalismo econômico, na versão mais pura de capitalismo de que o mercado deve funcionar livremente, sem interferência, taxas nem subsídios, apenas com regulamentos suficientes para proteger os direitos de propriedade. https://pt.wikipedia.org/wiki/Laissez-faire.
} 
composta por 9 pessoas, sendo, o avô - velho apelidado de Boa Morte em razão de ter-lhe escapado por três vezes -, seu filho Maheu, a esposa e 6 filhos desse casal.

Apesar de tratar secundariamente de uma história de amor entre a filha mais velha de Maheu, Catherine, e o jovem Etienne, a obra tem por principal enfoque a questão social do trabalho em condições desumanas, da germinação dos movimentos sociais e das lutas de classe que serviram de base à ampliação dos direitos políticos e à formação e ao reconhecimento normativo-constitucional dos direitos sociais.

Portanto, a ambientação do livro alterna-se entre a Mina de Voreux e o aglomerado habitacional onde moram os trabalhadores, mostrando com grande fidelidade a situação de desumanidade do trabalho na mineração pela visão da dura rotina enfrentada por 5 dos membros da família Maheu, os quais deixavam sua casa de madrugada, 6 dias por semana, retornando somente após o anoitecer, o que explica algumas passagens da obra em que o sol é referido como melancólica lembrança dessas personagens.

Voltando-se novamente à frase inicial, cumpre esclarecer que a pseudo benevolência patronal a que se refere a mulher, diz respeito à ocupação que lhe fora dada na mina de Voreux, após ter perdido o marido e dois dos três filhos que eram economicamente produtivos e lá trabalhavam, em um desastre provocado no contexto de uma greve dos mineiros, o que a obrigou a buscar ocupação remunerada a fim de subsistir.

\footnotetext{
Fora por caridosa exceção que a companhia, apiedada pela sorte daquela infeliz, permitira que voltasse a trabalhar na idade de quarenta anos. E, como parecia difícil usá-la no carreio, empregaram-na para acionar um pequeno ventilador que acabavam de instalar na galeria norte, na região infernal do Tartaret, onde não havia ventilação. Durante dez horas, com os rins alquebrados, ela fazia a roda girar, no fundo daquele buraco ardente, com o corpo cozido por quarenta graus de calor. Ganhava trinta soldos (ZOLA, 2012, p 404).
}

A fala da mulher torna-se mais trágica ao afirmar: "Os vinte soldos do menino aquele que sobreviveu à tragédia - e os meus trinta soldos fazem cinqüenta. Se não fôssemos seis teríamos o que comer" (ZOLA, 2012, P. 404). A possibilidade de alimentar-se constitui a única aspiração de vida dessa personagem, quer apenas manter-se viva, não há outra busca existencial retratada a priori, marcadamente só esta, como se confirma no diálogo a seguir:

Quando Etienne a viu, deplorável naquelas roupas masculinas, com os seios e a barriga como que inchados pela umidade da mina não conseguiu falar de tanto espanto, não encontrou palavras para dizer que partia e desejava despedir-se dela. A mulher encarou-o, impassível, e por fim disse, tuteando-o: — Como é, estás 
admirado de me ver? É verdade que eu ameaçava matar o primeiro dos meus que voltasse à mina, e aqui estou eu. Devia matar-me, não achas? Asseguro-te que já o teria feito, se não fossem o velho e as crianças para alimentar.

O diálogo descrito ocorre nas páginas finais do livro e tem por interlocutor da mulher, como visto, a personagem principal, Etienne - jovem idealista responsável por fomentar no coração dos mineiros o desejo da luta social, revelando, com clareza, a desigual formação das classes sociais da época e a vocação de miserável permanência do proletariado à margem da cidadania proclamada pelo liberalismo econômico e, que assim era mantida pelo círculo vicioso da necessidade, o que se torna claro quando a mulher conclui: " mas o pior é que terei de esperar quatro ou cinco anos para que Lénore e Henri estejam em idade de trabalhar" (ZOLA, 2012, p. 404)

Estes dois filhos citados pela mulher de Maheu eram crianças e, ainda nessa condição, logo seriam inseridos no mercado de trabalho, não seriam poupados da miséria, nem tampouco incluídos nas benesses do capitalismo sem lutar, pois se forjava cada vez com mais rigor a desigualdade social, a qual, segundo Marshall (1967), seria necessária e proposital, corroborando a afirmação de Colquhoun (apud MARSHALL, 1967, p. 78), no sentido de que, sem que haja pobres, não há como existir ricos, já que estes seriam o produto do trabalho e o trabalho, resultaria tão somente da pobreza.

Pode-se observar que a história narrada no citado livro se passa durante a vigência do Estado Liberal de Direito, quando foram erigidos à categoria de fundamentais os direitos civis, que se constituíam em direitos de liberdade; portanto, contratar era uma liberdade, incluindo o contrato de trabalho, não se admitindo que o Estado interviesse na seara individual para impor limites à livre concorrência, como, por exemplo, pela estipulação de um salário mínimo ao trabalhador.

Portanto, os primeiros direitos fundamentais constitucionalmente reconhecidos foram os direitos civis, caracterizado pelo direito de liberdade - de pensamento, expressão, crença, locomoção, propriedade, acesso à justiça, etc.. Os problemas sociais não interessavam ao Estado, que, conforme Bastos (2007), não era intervencionista, pois se acreditava que, deixando que as pessoas agissem com total liberdade, seria possível a distribuição mais justa das riquezas.

Novamente fazendo menção à obra "Germinal", pode-se observar que, naquele cenário fictício e ao mesmo tempo tão real, a ideia de distribuição justa de riquezas não havia se concretizado. 
Vianna (2005) aponta que a liberdade e a igualdade, asseguradas pelo Estado apenas no plano teórico, garantiam à classe capitalista a força econômica capaz de submeter, pela necessidade de subsistência, todos os trabalhadores que compunham o proletariado, explorando-os e escravizando-os sem qualquer preocupação com as suas condições de vida, sendo-lhes indiferente, como se não vivessem no mesmo mundo, pois:

\begin{abstract}
Em seu super mundo, em monopólio absoluto, os ricos evocavam para si todos os favores e todas as benesses da civilização e da cultura: a opulência e as comodidades dos palácios, as fortunas transbordantes das ucharias, as galas e os encantos da sociabilidade e do mundanismo, as honrarias e os ouropéis das magistraturas do Estado. Em suma: a saúde, o repouso, a tranquilidade, a paz, o triunfo, a segurança do futuro para si e para os seus. No seu inframundo repululava a população operária: era toda uma ralé fatigada, sórdida, andrajosa, esgotada pelo trabalho e pela subalimentação; inteiramente afastada das magistraturas do Estado; vivendo em mansardas escuras, carecidas dos recursos mais elementares de higiene individual e coletiva; oprimida pela deficiência dos salários; angustiada pela instabilidade do emprego; atormentada pela insegurança do futuro próprio e da prole; estropiadas pelos acidentes sem reparação; abatida pela miséria sem socorro; torturada na desesperança da invalidez e da velhice sem pão, sem abrigo, sem amparo (...) (VIANA apud VIANNA, in SÜSSEKIND et al., 2005, p 34/35).
\end{abstract}

Essa assombrosa realidade social é também descrita por Zola (2012), nas passagens que mostra a burguesia em seu glamour e riqueza admirável, em contraste com a absoluta miséria da classe trabalhadora, cuja aproximação mais relevante se esvazia na menção à caridade praticada por aquela, conforme sintetiza Engels quando se refere à organização da sociedade civilizada e do Estado Liberal:

\footnotetext{
Quanto mais progride a civilização, mais se vê obrigada a encobrir os males que traz necessariamente consigo, ocultando-os com o manto da caridade, enfeitando-os ou simplesmente negando-os. Em uma palavra: elabora-se uma hipocrisia convencional, desconhecida pelas primitivas formas de sociedade e pelos primeiros estágios da civilização, que culmina com a declaração de que a classe opressora explora a classe oprimida exclusiva e unicamente para o próprio benefício desta. E, se a classe oprimida não o reconhece, e até se rebela, isso, além do mais, revela sua mais negra ingratidão para com seus benfeitores, os exploradores (ENGELS, 2002, p. 62).
}

Marshall (1967) aponta que, nesse período, os direitos civis não conflitavam com as desigualdades impostas pelo capitalismo, ao contrário, estes direitos eram necessários à manutenção de tal desigualdade, ou seja, ao se assegurar constitucionalmente os direitos civis, positivou-se a desigualdade social, sob a rubrica de "igualdade formal", e se tornou a "liberdade" um elemento novo de opressão da classe trabalhadora, como referiu Engels (2002). 
A obra "Germinal" traz à baila essas questões pelo viés dos movimentos sociais dos trabalhadores no mundo ocidental do século XIX, os quais lutaram por melhores condições de trabalho e salários, aparecendo na obra representados por um movimento grevista fomentado pelo espírito de liderança do jovem Etienne, na tentativa de criar naqueles trabalhadores o desejo de mudança política e de melhorias materiais. Note-se que, mesmo diante do fracasso da greve e da tragédia ocorrida com um acidente provocado nas minas de Voreux, que ceifou várias vidas, incluindo a de seu amor Catherine, ele mostra que a centelha lançada, havendo condições propícias, germina.

E, sob seus pés, continuavam as batidas cavas, obstinadas, das picaretas. Todos os companheiros estavam lá no fundo; ouvia-os seguindo-o a cada passo [...]. E ainda, cada vez mais distintamente como se estivessem mais próximos da superfície, os companheiros cavavam. Sob os raios chamejantes do astro rei, naquela manhã de juventude, era daquele rumor que o campo estava cheio. Homens brotavam, um exército negro, vingador, que germinava lentamente nos sulcos da terra, crescendo para as colheitas do século futuro, cuja germinação não tardaria em fazer rebentar a terra (ZOLA, 2012, p. 409).

Esse desfecho do livro, de modo figurado, faz alusão às lutas de classe que foram decisivas para a implantação do Estado Social de Direito, uma nova ideologia baseada na solidariedade, como ensina Atria (2005). O Welfare State é o reconhecimento definitivo da dignidade da pessoa humana como fundamento de uma nova ordem social que irrompe no alvorecer do século XX.

Portanto, este é o momento histórico em que se agrega à cidadania o seu terceiro elemento de formação conceitual, sendo que esse conceito ideal de cidadania apontado por Marshall (1967), muito embora possa não corresponder à realidade brasileira - como se verá em seguida -, nas palavras de Carvalho (2008, p. 9), serve de "parâmetro para o julgamento da qualidade da cidadania em cada país e em cada momento histórico".

\section{A CONSTRUÇÃO DA CIDADANIA BRASILEIRA.}

A construção da cidadania enquanto direito fundamental no Brasil não foi concomitante à dos países mais desenvolvidos, especialmente os europeus, conforme adverte Fachin (2002, p. 16), ao afirmar que "ingressamos no século XXI com os pés atolados no fim

\footnotetext{
${ }^{2}$ Estado de bem-estar.
} 
da baixa idade média", acrescentando que foram cinco séculos de construção de um conceito de não cidadania ou, pelo menos, de uma cidadania atrofiada.

A situação não mudou efetivamente com o reconhecimento formal dos direitos políticos e sociais, os quais garantiriam uma proteção mínima e uma vida decente, pela $\mathrm{CF} / 88$, o que permite concluir que há uma sensível distância entre essas prerrogativas e a realização social dos direitos de liberdade, educação, saúde, trabalho, acesso à justiça, ou seja, da realização do direito de viver com dignidade (FACHIN, 2002, p. 17).

Corroborando essas assertivas, Carvalho (2008) afirma que foi só a partir do ano de 1985, com o fim da ditadura militar, que houve o fortalecimento efetivo da democracia no Brasil, bem como do conceito de cidadania, que deu ensejo à crença de que a democratização do país garantiria a liberdade de participação, segurança, desenvolvimento e emprego, enfim, a justiça social. Porém, com exceção dos direitos de liberdade e políticos, que se fortaleceram grandemente, não restaram efetivadas as soluções de diversos problemas sociais, como a violência, o desemprego, a má qualidade da educação e da saúde, dentre outros.

A partir das considerações de Marshall (1967), Carvalho (2008) salienta que, em tese, a plenitude da condição de cidadão seria alcançada pelo titular desses três direitos, o possuidor de apenas alguns deles seria um cidadão e incompleto, ao passo que seriam nãocidadãos os que não se beneficiassem de nenhum deles.

Para Carvalho (2008), quanto à formação da cidadania no Brasil, o primeiro ponto relevante é definir, em termos históricos, a diferença substancial em relação àquela apresentada por Marshall (1967) para a cidadania europeia. Explica que a ordem em que os elementos da cidadania são paulatinamente conquistados se inverte na realidade nacional, sendo o elemento social o primeiro a ser inserido no conceito, além de destacar que a formação completa da cidadania somente começa a ser conquistada em fins do século XX, quando já se encontra sedimentada nos países desenvolvidos.

Pela leitura de Carvalho (2008), pode-se inferir que o atraso acima mencionado, bem como a inversão da ordem em que os elementos da cidadania são efetivamente inseridos no conceito de cidadão, deve-se ao fato de o Brasil ter sido colônia de Portugal até o século XIX, com natureza econômica mercantilista e sem conteúdo ideológico, o que seria essencial à sedimentação dos direitos civis.

Ademais, a sociedade era latifundiária e escravocrata, sendo que ao escravo sequer era reconhecida a condição de pessoa humana, quanto mais de cidadão. Mesmo à população 
livre, que se posicionava entre o escravo e o senhor, faltava a "liberdade substancial" no sentido de autonomia ideológica e mesmo material para o exercício dos direitos, vez que completamente dependente dos grandes proprietários. Ao senhor faltava o sentido próprio de cidadania, pois embora livre, sua força imperativa "terminava na porteira das grandes fazendas" (CARVALHO, 2008, p. 21).

A declaração da independência, em 1822, não trouxe nenhuma mudança muito acentuada, permanecendo a mesma política latifundiária, com baixa consciência política do povo, o que, segundo Carvalho (2008), teve como fator decisivo o fato de a educação ter sido negligenciada por completo durante o período colonial, não havendo também desenvolvimento significativo após a independência, pois meio século depois desta, apenas $16 \%$ da população brasileira era alfabetizada, não interessando aos senhores a educação de seus escravos, para não difundir essa verdadeira "arma cívica” (CARVALHO, 2008, p. 23).

Por certo esse fato é relevante no contexto da cidadania e talvez possa justificar o atraso do Brasil em relação aos países europeus, pois, segundo Marshall (1967), a emancipação política e social da Europa passou necessariamente pela educação, conquistada como um direito característico da cidadania.

A emancipação civil e política da sociedade brasileira continuou enfrentando obstáculos ainda ligados à sua formação e à distribuição do poder desde a independência até pelo menos o fim da primeira república, apesar de, desde a Constituição outorgada de 1824 formalmente, havia um ensaio de cidadania devido à imposição europeia ao Brasil de um governo representativo baseado no voto e na separação dos poderes (CARVALHO, 2008).

$\mathrm{Na}$ verdade, até a primeira república, é questionável a qualidade do direito político garantido ao eleitorado, que era composto da mesma população colonial, analfabeta e despreparada para o exercício do voto. Eram “convocados" pelos patrões e demais autoridades para votarem naqueles que indicavam, de modo que o voto perdia totalmente seu significado político, era um ato de obediência, ou, na melhor das hipóteses, de lealdade (CARVALHO, 2008).

Consoante Carvalho (2008), pode-se concluir que, até 1930, a organização política era quase inexistente no Brasil, do mesmo modo que era inconsistente o sentimento de nacionalidade e o povo suspeitava do governo ou a ele se opunha, podendo-se afirmar que havia uma "cidadania em negativo" (p. 83), e que o Brasil para o povo ainda era uma realidade abstrata. 
De todo o exposto até aqui, pode-se inferir que, desde o período colonial havia no Brasil uma estruturação de classes sociais bem definida, ainda que não organizada politicamente e, muito embora o país não possuísse o nível de industrialização da experiência capitalista européia, no que diz respeito à exploração do trabalho humano, o país igualava-se às nações capitalistas desenvolvidas.

Desse modo, do ponto de vista da historicidade, o desenvolvimento da sociedade confunde-se com a própria história do trabalho, o qual, como força física voltada à proteção e à sobrevivência, existe desde os primórdios da humanidade (CASSAR, 2014). Porém, foi somente com o nascimento do Estado Liberal de Direito e a implantação do liberalismo de mercado e do assalariamento que o trabalho assumiu a feição de mercadoria, conforme assinala Bastos (2007), ao afirmar que, no capitalismo, a venda do trabalho era a única forma de participação da classe trabalhadora no mercado.

O trabalho humano é, sem dúvida, o ponto nevrálgico do desenvolvimento da cidadania e da sociedade e, no Brasil, sempre esteve visceralmente ligado à formação e ao predomínio da classe proprietária sobre a classe trabalhadora, com o ingrediente complicador da estendida escravidão, a qual foi ignorada por completo pelas constituições imperiais, deixando de existir de modo definitivo somente em 1888 em virtude de pressões internacionais, quando já não teve grande impacto social, em razão do baixo quantitativo de escravos existentes no Brasil à época (CARVALHO, 2012).

Igualmente tardio foi o desenvolvimento da cidadania, que iniciou em 1930, com a criação do Ministério do Trabalho, Indústria e Comércio, e de vasta legislação trabalhista e previdenciária, culminando com a implantação da Consolidação das Leis do Trabalho, no ano de 1943.

No lapso temporal compreendido entre 1930 e a instauração da ordem constitucional vigente no país (1988), houve uma alternância entre regimes ditatoriais e democráticos, causando certa instabilidade em relação aos direitos políticos. Quanto aos direitos civis, Carvalho (2008) afirma que:

Os direitos civis progrediram lentamente. Não deixaram de figurar nas três constituições do período, inclusive na ditatorial de 1937. Mas sua garantia na vida real continuou precária para a grande maioria dos cidadãos, durante a ditadura, muitos deles foram suspensos, sobretudo a liberdade de expressão de pensamento e de organização (p. 88). 
Assim, segundo o autor, enquanto se alternavam os regimes de governo, alternava-se também a importância dos direitos políticos e dos direitos sociais, verificando-se que, nos governos militares, houve a compensação da falta de liberdade política pela implementação das políticas sociais, enquanto os direitos civis foram amplamente cerceados, o que causou consideráveis retrocessos na construção da cidadania.

Mas foi também durante essa época que se fortaleceram as bases sindicalistas e os movimentos operários dos setores novos da economia, como as grandes montadoras multinacionais e as siderúrgicas. Iniciaram-se os movimentos no final da década de 1970, com reivindicações por melhorias salariais que culminaram em um processo grevista de grande monta, incluindo até mesmo trabalhadores rurais. Em 1979, os grevistas somavam mais de três (3) milhões de trabalhadores de diversas categorias profissionais, que, em última análise, lutavam por cidadania (CARVALHO, 2008).

A última fase da história da formação da cidadania, segundo Carvalho (2008), corresponde ao nascimento de uma nova ordem social inaugurada no Brasil com a promulgação da Constituição Federal de 1988, que sedimentou o Estado Democrático de Direito, o qual, pelo menos em termos teóricos, reconhece ao brasileiro a mais genuína forma de cidadania, contemplando, em sua substância ideal, os três elementos apresentados por Marshall (1967), - civil, político e social.

Considerada a constituição cidadã, a Carta Constitucional de 1988, é a mais liberal e democrática já vista no Brasil, pois consagrou a ampliação dos direitos políticos, incluindo a facultatividade do voto ao analfabeto, menor - entre 16 e 18 anos - e idoso, ampliando também a liberdade na organização político-partidária, a fim de excluir óbices ao exercício da democracia além da liberdade de associação, que tornou possível o surgimento de movimentos sociais.

Em que pese a cidadania esteja sedimentada em nosso país, Fachin (2002) destaca a necessidade de construir-se uma ponte entre o sujeito-virtual e o sujeito-cidadão, pois a democratização do país não resolveu, automaticamente, os inúmeros problemas sociais, especialmente os decorrentes da imensa desigualdade existente no Brasil desde o período colonial. Há uma gritante disparidade entre o produto interno bruto e a renda per capita, tendo como resultado a escandalosa riqueza de uns, em contraste com "níveis dolosos de pobreza e miséria" (CARVALHO, 2008, p. 208). 
De igual modo, as desigualdades sociais não desapareceram simplesmente porque os direitos sociais ganharam normatividade constitucional, De fato, conforme adverte Sarlet (2014), a mera previsão constitucional dos direitos sociais e dos trabalhadores ainda que contem com um sistema próprio de garantias, não foi suficiente, por si só, para impedir seu déficit de efetividade, o que se revela claramente na atividade de mineração, na qual o aviltamento dos trabalhadores constitui óbice ao exercício real da cidadania, como se demonstrará.

\section{O TRABALHO NA MINERAÇÃO NO BRASIL CONTEMPORÂNEO: CIDADANIA.}

Os direitos sociais especialmente os direitos trabalhistas no Brasil, como visto anteriormente, foram forjados - como acontece em regra -, em lutas de classes pelo sindicalismo, organização político-partidária, greves trabalhistas e outro movimentos sociais pela redemocratização do país que culminou com a instauração de nova ordem constitucional (1988) que nos dizeres de Sarlet (2014, p. 16) "foi inequivocamente amiga dos direitos sociais e dos direitos dos trabalhadores".

Embora os movimentos sociais tenham tido êxito na conquista da democracia, fazendo crer que esse novo sistema político permitiria a manutenção e ampliação da cidadania, estabeleceu-se um novo modelo de dominação, bem mais sutil, que é ditadura de mercado, a qual não deve ser ignorada sob pena de se ignorar a lógica que sustenta o capitalismo, que é a do dominador/dominado (MONTEIRO et al., 2006).

Nesse ponto é indubitável o reconhecimento de que, o dever de proteção, mesmo diante do arcabouço jurídico constitucional em defesa do trabalhador, não seja suficiente para equilibrar a luta travada entre capital e força de trabalho, como adverte Weber (apud COUTINHO, 2014, p. 82:

\footnotetext{
A "escravidão moderna" é mais sutil do que a do século XIX, o cerceamento a liberdade pode decorrer de diversos constrangimentos econômicos e não necessariamente físicos. Priva-se alguém de sua liberdade e de sua dignidade tratando-o como coisa e não como pessoa humana, o que pode ser feito não só mediante coação, mas também pela violação intensa e persistente de seus direitos básicos, inclusive do direito ao trabalho digno. A violação do direito ao trabalho digno impacta a capacidade da vítima de realizar escolhas seguras a sua livre determinação. Isso também significa reduzir alguém à condição análogo a de escravo (Inq. 3412, rel. p/o AC.min. Rosa Weber, julgamento em 29-03-2012, plenário, DJe de29-03-2012) (WEBER, apud COUTINHO, 2014, p. 82).
} 
O conceito atual de trabalho escravo, consoante o artigo 149 do Código Penal, abrange, sem qualquer dúvida, as situações de trabalho prestadas em condições aviltantes, que tornam precários ou suprimem direitos fundamentais do trabalhador, tal qual retratado em "Germinal", na mineração, e persiste no cenário brasileiro, conforme denunciado por Koury (2014):

\begin{abstract}
As novas formas de produção e de gestão do trabalho, típicas da década de 1990, auge da liberalização comercial e financeira do Brasil, que acabaram por precarizar o mercado de trabalho, também se fizeram sentir na Amazônia Oriental, com as grandes empresas mineradoras, em especial, a Vale S/A, líder inconteste, privatizada em 1997, passando a recorrer a toda sorte de terceirização de atividades e à transferência de responsabilidades para as empresas contratadas e subcontratadas (KOURY, 2014, p. 2014).
\end{abstract}

A autora, ao referir-se às minas de ferro de Carajás exploradas pela empresa Vale S/A, aponta uma gama de violações dos direitos dos trabalhadores, além de outros problemas relevantes ligados ao contexto socioambiental da mineração, tais como a inexistência de crescimento econômico duradouro nas regiões de mineração, dado o aumento do trabalho informal e da terceirização massiva da mão de obra, tendo como consequência a precarização de direitos básicos do trabalhador.

Uma simples comparação da realidade atual com a retratada na obra "Germinal" permite identificar que os problemas comuns da mineração persistem, tais como o grau de risco à saúde, que, em Germinal, aparece quando se trata da saúde pulmonar do velho "Boa Morte", extremamente afetada pelos resíduos das minas. Consoante Lucon (apud COSTA, REZENDE, 2012), os problemas relativos ao meio ambiente do trabalho persistem. Vejamos:

\footnotetext{
A atividade mineradora, principalmente aquela que submete os trabalhadores a permanecerem dentro de minas subterrâneas, provoca vários tipos de doenças pulmonares, devido à exposição a agentes físicos, químicos e biológicos. Dependendo do tempo de exposição, não haverá tratamento adequado para sua cura. [...] Os danos físicos caracterizam-se pelas extremas temperaturas calor, umidade, iluminação, ruídos, vibrações e riscos ergonômicos (posturas inadequadas e movimentos repetitivos). Todos esses agentes e particularmente a temperatura, em minas rochosas, aumenta $1^{\circ}$ grau para cada 100 metros de profundidade. Pode-se imaginar o desconforto desse ambiente de trabalho (LUCON apud, COSTA, REZENDE, 2012, P. 775).
}

A insegurança do trabalhador também é retratada por Zola (2012) em várias passagens, como as que tratam do calor excessivo, da baixa iluminação, da insegurança dos cabos e elevadores abertos, dentre muitos outros, que ainda são enfrentados na atualidade, o que resta patente pelo fato de a atividade de mineração, conforme classificação do Ministério 
do Trabalho, liderar no número de acidentes e mortes no trabalho, ocupando o último nível na escala de risco (SILVA, 2011).

Os acidentes são muitos, e em casos pontuais, podem sugerir a falta de prevenção ou desrespeito às normas de segurança do trabalhador, como é o caso da mineração no Estado de Minas Gerais que no ano de 2007 teve um aumento de 15,3\% sendo registrado neste Estado, 1.090 acidentes, enquanto, em termos nacionais, o aumento foi de 3,8\%, registrando-se no restante do país 1.050 acidentes (COSTA, REZENDE, 2012).

Sem questionar a importância da atividade de mineração para o desenvolvimento do país, outro ponto confirmado por Silva (2011), é que, mesmo no contexto da produção e consumo capitalista, a despeito do grande lucro auferido pela indústria da mineração, esta não promoveu melhorias na qualidade de vida no território explorado, ao contrário, algumas regiões se encontram em faixas de grande carência e subdesenvolvimento.

Dentro do contexto da cidadania assume relevância essa questão em razão da necessidade de diminuir as desigualdades sociais como forma de alcançar a cidadania real, sendo um dos meios mais eficazes para tal, o trabalho digno; porém, no contexto da mineração, pode-se vislumbrar exatamente o contrário, como demonstrado por Koury (2014) ao fazer breve relato da realidade social captada pelo Jornalista Carlos Barros na cidade de Parauapebas, quando constata o luxo da cidade construída para o alto escalão da Vale S/A., em contraste com a miséria habitacional dos lugares destinados ao abrigo dos demais trabalhadores.

Um estudo de direitos humanos realizado em 2013 na região ocupada pela mineração em Carajás, acusa a empresa Vale S/A, maior mineradora do país, de desrespeitar a legislação trabalhista, além de muitos outros infortúnios trazidos à população direta e indiretamente envolvida no empreendimento, tais como, o aumento da violência, doenças, prostituição, miséria, subemprego, dentre outras males que, por certo, afetam com exclusividade a classe explorada (FAUSTINO, FURTADO, 2013).

Assim, a resposta à pergunta-problema que norteou esse estudo não pode ser outra: a cidadania garantida pela Constituição Federal de 1988 não é assegurada no contexto real do embate entre o capital e a força de trabalho, na atividade de mineração, pois há garantia apenas de liberdade estrita e de igualdade meramente formal, persistindo os problemas que foram detectados por Zola em Germinal. 


\section{CONSIDERAÇÕES FINAIS.}

De todo o exposto até aqui, pode-se inferir que a cidadania no Brasil ainda encontrase em construção, pois o sujeito-virtual está bem mais amparado pela lisonjeira eloqüência do texto constitucional, do que o sujeito-cidadão, aquele feito de realidade, de pé no chão, que batalha diariamente pela subsistência própria e de sua família.

Com a Carta Cidadão como afirma Carvalho "a cidadania virou gente" a cidadania deseja, espera, requer, isso mesmo, requer sejam transpostas as barreiras da desigualdade social, do desrespeito à dignidade da pessoa humana, do trabalho escravo, não daquele em que a coação física impera, mas daquela escravidão sutil, que de escancarada durante o liberalismo econômico, passou a ser dissimulada pela precarização ou supressão de direitos trabalhista.

A cidadania brasileira não foi construída por meio daquele processo lógico de Marshall (1967), pelo qual os direitos civis, antecederam os políticos e estes aos direitos sociais, nem tampouco obedeceu à ordem cronológica apontada pelo autor - séculos XVIII, XIX e XX - No Brasil a cidadania "plena" - composta dos três elementos - foi conquistada em tempos bem recentes com a Constituição de 1988, que vige atualmente no país.

Mas, dúvidas restam poucas, de que esta cidadania reconhecida constitucionalmente aos brasileiros, não tem, por si só, o poder de fazer com que se cumpram, no contexto real da vida, as promessas de justiça social.

O elemento crítico da cidadania brasileira é o elemento social. Os direitos sociais, especialmente quando se trata de trabalho, não necessariamente de emprego, onde ocorre o embate entre o capital e a mão de obra, nota-se que a cidadania fraqueja, perdendo seu vigor diante da força do capital, que gera gritantes desigualdades sociais.

Essas desigualdades são sentidas de forma ainda mais acentuada, quando o trabalho por sua natureza vulnerabiliza o trabalhador, que é o que ocorre nas atividades da mineração, pelo alto grau de risco à saúde e segurança do trabalhador, mas este não é o cerne do problema, deve-se ater, ao passivo socioambiental alarmante gerado pela mineração no Brasil atualmente.

Este passivo representa séria ameaça à cidadania dessa categoria de trabalhadores, além de alcançar todos os que são direta e indiretamente afetados pelos empreendimentos 
mineradores, que desrespeitam desde direito básicos do trabalhador até a vida humana como que se estivesse tratando com simples coisas.

\section{REFERÊNCIAS.}

ATRIA, F. Existen Derechos Sociales? Edición digital a partir de Discusiones: Derechos Sociales, núm. 4 (2005), pp. 15-59. Alicante : Biblioteca Virtual Miguel de Cervantes, 2005. Disponível em: http://www.cervantesvirtual.com/obra/existen-derechos-sociales-0/ Acesso em 01.04.2019.

BASTOS, E, A, V. O Constitucionalismo Social A Constituição como Instrumento Jurídico de Contenção do Poder Econômico. In: GASTARDO, Hamilton Fernando Gastardo et al (COORD). Lições de Direito Constitucional em Homenagem ao Prof. Dr. Sérgio Resende de Barros. Campinas: Milenium, 2007.

BARRETO, V, P. O fetiche dos direitos humanos e outros temas. 2. ed. Porto Alegre: Livraria do Advogado, 2013.

CARVAlHO. J, M. Cidadania no Brasil: O longo caminho. 11 ed. Rio de Janeiro: Civilização Brasileira, 2008.

CASSAR, V, B. Direito do Trabalho. 09 ed. São Paulo: Método, 2014.

COUTINHO, A. R. A dimensão do princípio da dignidade e a relação de trabalho. In SARLET, Ingo Wolfgang; MELO FILHO, Luiz Philippe Vieira de; FRAZÃO, Ana de Oliveira (COORD). Diálogo Entre Direito do Trabalho e Direito Constitucional. São Paulo: Saraiva, 2014.

COSTA, B, S.; REZENDE, E, N. MEIO AMBIENTE DO TRABALHO E A SAÚDE DO TRABALHADOR NA MINERAÇÃO BRASILEIRA. RIDB- Revista do Instituto do Direito Brasileiro. Lisboa, Ano 1 (2012), nº 2, 759-792. 
FACHIN. L, E. Família, Direitos e Uma Nova Cidadania. In: PEREIRA, Rodrigo da Cunha (COORD). FAMÍlIA E CIDADANIA - O NOVO CCB E A VACATIO LEGIS. Anais do III Congresso brasileiro de direito de família. Belo Horizonte: Del Rey / IBDFam - Instituto brasileiro de direito de família, 2002.

FAUSTINO, C.; FURTADO, F. Mineração e violação de direitos: O projeto ferro Carajás s11d, da vale s/a. Açailândia, 2013. Disponível em: http://www.global.org.br/wpcontent/uploads/2016/03/plataforma-dhesca_carajas.pdf. Acesso em: 15 jun. 2018.

ENGELS, Friedrich. A origem da Família da Propriedade Privada e do Estado. São Paulo: Centauro, 2002.

KOURY, S, C. Meio ambiente e condições de trabalho na Amazônia oriental: uma análise sobre as relações de trabalho na mineração. Rev. TST, Brasília, vol. 80, no 2, abr/jun 2014. Disponível em: https://juslaboris.tst.jus.br/handle/20.500.12178/65639. Acesso em: 05 Set. 2018.

MARSHALL, T. H. Cidadania, Classe Social e Status. Rio de Janeiro: Zahar, 1967.

MONTEIRO, A, M, ; COIMBRA, C, C, ; FILHO, M, M, F. Estado Democrático de Direito e Políticas Públicas: Estatal é necessariamente público?Psicologia \& Sociedade, 18(2), mai./ago. 2002, p. 26. Cadernos de Direito, Piracicaba, v. 17(33): 3-27, jul.-dez. 2017 • ISSN Eletrônico: 2238-1228. Disponível em: http://www.scielo.br/pdf/psoc/v18n2/01.pdf. Acesso em: 20 de jan. 2019.

SARLET, I, W. Os direitos dos trabalhadores como direitos fundamentais na Constituição Federal brasileira de 1988. In SARLET, Ingo Wolfgang; MELO FILHO Luiz Philippe Vieira de; FRAZÃO Ana de Oliveira (COORD). Diálogo Entre Direito do Trabalho e Direito Constitucional. São Paulo: Saraiva, 2014. 
VIANNA, Segadas.; SUSSEKIND, Arnaldo et al. Instituições de Direito do Trabalho. 22 ed. São Paulo: LTr, 2005.

VIEIRA, L, A. A (in)sustentabilidade da Indústria da Mineração no Brasil. Estação Científica (UNIFAP) Macapá, V1, N2, P. 01-15, 2011. Disponível em: file://C:/Users/Rafael\%20Almeida/Downloads/248-1053-2-PB\%20(2).pdf. Acesso em: 10 junh. 2018.

ZOLA. E. Germinal. Coleção: A obra-prima de cada autor. BPI - biblioteca pública independente. São Paulo: Martin Claret, 2012. Disponível em: http://ciml.250x.com/archive/literature/portuguese/zola_germinal.pdf. Acesso em: 20 de Ago. 2018. 